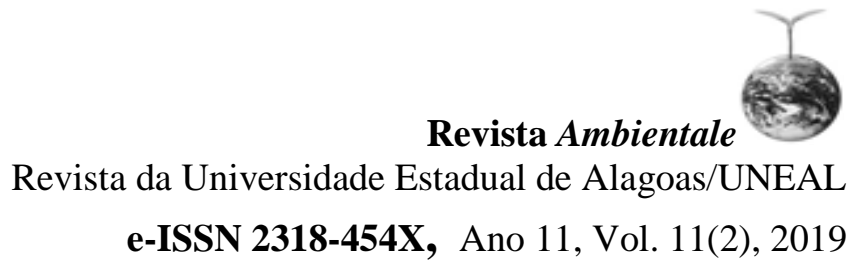

\title{
Levantamento fitossociológico de plantas daninhas na cultura do maracujá
}

\author{
Phytosociological survey of weeds in passion fruit culture
}

\author{
Thaís Rayane Gomes da SILVA ${ }^{1}$; Marcelo Rodrigues BARBOSA JÚNIOR ${ }^{1}$; Rayane Stefane da \\ Silva SANTOS ${ }^{1}$; Fernanda Ferreira da SILVA ${ }^{1}$; Paulo Henrique Vieira ARAUJO ${ }^{1}$; Valdevan \\ Rosendo dos SANTOS ${ }^{2}$

\footnotetext{
${ }^{1}$ Graduandos do curso de Agronomia, Universidade Federal de Alagoas, Campus Arapiraca. E-mail: tsgomes4@gmail.com; marcelojragro@gmail.com; rayaaness2@gmail.com; nandaferreiranunes@gmail.com; paulinhuvieira2@gmail.com

${ }^{2}$ Professor da Universidade Federal de Alagoas, Campus Arapiraca. E-mail: valdevan@arapiraca.ufal.br *E-mail: tsgomes4@gmail.com (autor correspondente)
}

Resumo - O problema com plantas daninhas é um dos mais sérios e que são responsáveis pelos maiores gastos em seu controle, pois a disputa por água, nutrientes e luz pode causar uma diminuição significativa no rendimento da lavoura, depreciação na quantidade e na qualidade dos frutos. Desta forma, objetivou-se realizar o levantamento fitossociológico das plantas daninhas em área cultivada com a cultura do maracujá, na Universidade Federal de Alagoas - UFAL, Campus de Arapiraca. Foram realizadas 6 amostragens com quadrado vazado de $0,50 \mathrm{~m}^{2}$, onde as plantas daninhas foram coletadas ao nível do solo, separadas por espécie, contadas e levadas à estufa, até massa constante, para determinação da massa seca. A partir desses valores, determinaram-se as seguintes características: frequência de plantas daninhas, frequência relativa, densidade, densidade relativa, abundância, abundância relativa, massa seca relativa, índice de importância e índice de importância relativa. Foram identificadas 18 espécies e 10 famílias botânicas, sendo 13 dicotiledôneas e 5 monocotiledôneas, a família Asteraceae foi a mais representativa, seguida pela Poaceae. Entre as dicotiledôneas, a Asteraceae apresentou maior número de espécies infestantes com 6 espécies. Nicandra physaloides Gaertn. Solaneceae apresentou maior índice de importância relativa (IVIr), 94,88 e em seguida por Amaranthus hybridus L. Amaranthaceae com IVIr de 1,68. O menor valor de IVIr foi obtido por Sida spinosa L. Malvaceae.

Palavras-chave: Identificação. Maracujazeiro. Competição.

\begin{abstract}
The problem with weeds is one of the most serious ones and they are responsible for the greater expenses in their control, because the dispute over water, nutrients and light can cause a significant decrease in crop yield, depreciation in quantity and quality of the fruits. In this way, the objective was to carry out the phytosociological survey of weeds in an area cultivated with passion fruit, at the Federal University of Alagoas - UFAL, Arapiraca Campus. Six samples were taken with a $0.50 \mathrm{~m} 2$ cast square, where the weeds were collected at the soil level, separated by species, counted and brought to the oven, until constant mass, to determine the dry mass. From these values, the following characteristics were determined: weed frequency, relative frequency, density, relative density, abundance, relative abundance, relative dry mass, importance index and relative importance index. It was identified 18 species and 10 botanical families, being 13 dicotyledons and 5 monocotyledons, the family Asteraceae was the most representative, followed by Poaceae.
\end{abstract}




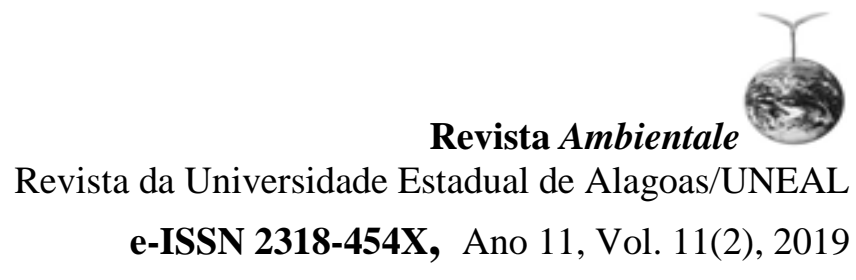

Among the dicotyledons, the Asteraceae had a higher number of infesting species with 6 species. Nicandra physaloides Gaertn. Solaneceae showed a higher index of relative importance (IVIr), 94,88 and then by Amaranthus hybridus L. Amaranthaceae with IVIr of 1.68. The lowest value of IVIr was obtained by Sida spinosa L. Malvaceae.

Key words: Identification. Passionflower. Competition.

\section{Introdução}

O maracujazeiro (Passiflora edulis Sims. Passifloraceae) é originário do Brasil e amplamente cultivado em todo o território nacional. A cultura do maracujá é cultivada comercialmente de norte a sul do território brasileiro, envolvendo regiões tropicais e subtropicais, que apresentam condições favoráveis para seu desenvolvimento, sendo o Nordeste responsável por mais de um terço da produção nacional (IBGE, 1999). De acordo com Faleiro e Junqueira (2016) a família do maracujazeiro é formada por 12 gêneros, sendo o gênero Passiflora o mais expressivo em número de espécies e importância econômica. Portanto, existem várias espécies de maracujazeiro (Passiflora spp.).

A cultura do maracujá vem ocupando um lugar de destaque na fruticultura tropical, um segmento que se expandiu como um todo nos últimos 30 anos. Considerada como uma alternativa agrícola interessante para a pequena propriedade é a fruteira que mais tem atraído os produtores. Representa uma boa opção entre as frutas por oferecer o mais rápido retorno econômico, bem como a oportunidade de uma receita distribuída pela maior parte do ano. A maioria das outras frutas leva alguns anos para entrar em produção, o que é incompatível com a necessidade imediata de renda dos produtores, descapitalizados com os prejuízos resultantes de outras atividades agrícolas (MELETTI et al., 2010).

O problema com plantas daninhas é um dos mais sérios e que são responsáveis pelos maiores gastos em seu controle, pois a disputa por água, nutrientes e luz pode causar uma diminuição significativa no rendimento da lavoura, depreciação na quantidade e na qualidade dos frutos. Segundo a Organização das Nações Unidas para Agricultura e Alimentação (FAO, 2018), essas plantas podem trazer perdas na produção global de alimentos de até U\$95 bilhões, valor maior do que representam os danos causados por doenças e insetos. Em um levantamento fitossociológico de plantas daninhas em áreas de produção de tomate rasteiro nos estados de Goiás, Minas Gerais e São Paulo, foram analisadas 69 áreas em 24 municípios, que juntos são responsáveis por $98 \%$ da produção de tomate para processamento industrial no Brasil.

A interferência dessas plantas pode resultar em perda de produtividade, menor qualidade do produto colhido ou aumento do custo de produção da cultura. A base para a formulação de uma eficiente proposta de controle é o conhecimento da flora daninha que ocorre nas áreas de cultivo (ADEGAS et al., 2010). As plantas daninhas são demasiadamente agressivas e várias são as características que expressam essa agressividade, possuem elevada capacidade de produção de sementes viáveis e adaptações especiais para disseminá-las, facilitando a dispersão. São plantas que possuem a elevada capacidade de competição e atributos específicos que assegurem a perpetuação, tais como dormência e germinação desuniforme (OLIVEIRA JÚNIOR et al., 2011). 


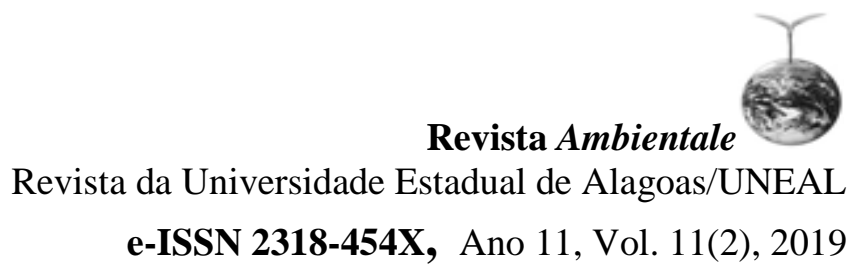

A cultura do maracujá é afetada por diversas espécies, gêneros, famílias e classes de plantas daninhas, normalmente essas causam prejuízos e danos a produção por meio de dois processos, sendo estes alelopatia e competição. Segundo Lima et al. (2004), a competição das plantas daninhas é um dos fatores que mais interferem na diminuição da produtividade e no aumento dos custos de produção.

O levantamento fitossociológico resulta em uma lista, com as espécies distribuídas de forma hierarquizadas, em função da sua posição relativa às demais, permitindo a interpretação quantitativa da estrutura da comunidade e suas relações ecológicas (GAMA, 2009). Esses estudos fitossociológicos são de fundamental importância, podendo ser identificada através destes, espécies ameaçadas, avaliar impactos e assim determinar técnicas de manejo, conservação.

Os estudos fitossociológicos comparam as populações de plantas daninhas num determinado momento. Repetições programadas dos estudos fitossociológicos podem indicar tendências de variação da importância de uma ou mais populações, e essas variações podem estar associadas às práticas agrícolas adotadas. A análise estrutural ou levantamento fitossociológico de uma determinada lavoura é muito importante para que se possam ter parâmetros confiáveis acerca da florística das plantas daninhas de um determinado nicho (OLIVEIRA e FREITAS, 2008).

Objetivou-se com este trabalho identificar e quantificar as espécies de plantas daninhas existentes em uma área experimental de cultivo de maracujá.

\section{Material e métodos}

O levantamento foi realizado em área experimental cultivada com maracujá na Universidade Federal de Alagoas - UFAL, Campus de Arapiraca, apresentando as seguintes coordenadas geográficas $\left(09^{\circ} 45^{\prime} 09^{\prime} \mathrm{S}, 36^{\circ} 39^{\prime} 40^{\prime} \mathrm{W}, 275 \mathrm{~m}\right)$. Esta região é caracterizada pela transição da Zona da Mata e o Sertão Alagoano, cujo clima é classificado como tipo "As" tropical, pelo critério de Köppen (1948). O solo é classificado como LATOSSOLO AMARELO VERMELHO Distrófico segundo a (EMBRAPA, 2006).

As plantas foram coletadas no mês de agosto de 2018, durante a fase de desenvolvimento da cultura do maracujá, após 6 meses de transplante das mudas. Para determinação das plantas a serem coletadas foi lançado aleatoriamente um quadrado vazado de tubo $0,5 \mathrm{~m}^{2}$, na cor marrom de $25 \mathrm{DN}$, em caminhamento aleatório na área. Foram realizadas 6 repetições e as plantas contidas dentro do quadrado lançado foram coletadas, com raiz, condicionadas em bandejas e levadas à ambiente adequado para ser realizada a identificação e contagem.

Para a identificação foi utilizado o manual de identificação e controle de plantas daninhas de Lorezzi. Depois de devidamente identificadas foram colocadas em estufa a uma temperatura de $65^{\circ}$ C, por um período de 48 horas. Após serem retiradas da estufa foi realizada a pesagem, aferindo-se a massa seca das plantas, no laboratório de química do solo da referida universidade.

Após a identificação das plantas foram calculados:

(Fre) Frequência de plantas daninhas $=\frac{\text { No de parcelas que contếm a espécie }}{\text { No total de amostras utilizadas }}$

(Frr (\%)) Frequência Relativa $=\frac{\text { Frequência da espécie } x 100}{\text { Frequêcia total de todas as espécies }}$ 
$\left(\right.$ Den $\left(\right.$ plantas $\left.\left.\mathrm{m}^{-1}\right)\right)$ Densidade $=\frac{\text { NQ de total de individuos por espécie }}{\text { Ârea total coletada }}$

$($ Der $(\%))$ Densidade Relativa $=\frac{\text { Densidade da espécie } x 100}{\text { Densidade total das espécies }}$

(Ab) Abundância $=\frac{\text { No total de indivíduos por espéciess }}{\text { No total de quadrados que contém a espécie }}$

(Abr (\%)) Abundância Relativa $=\frac{\text { Abundåncia da espécie } x \text { 100 }}{\text { Abundâneia total de todas as espécies }}$

$(\mathrm{Msr}(\%))$ Massa seca relativa $=\frac{\text { Massa seca da espécie } x \text { loo } 100}{\text { Massa seca total de todas as espécies }}$

(IVI) Índice de Importância $=($ Frr $)+($ Der $)+($ Abr $)+($ Msr $)$

(IVIr (\%)) Índice de Importância Relativa $=\frac{I V I * 100}{\text { IVI total de todas as espéciess }}$

Os dados obtidos foram tabulados e discutidos por análise descritiva. Foram construídas tabelas com o nome científico e família botânica de todas as plantas coletadas.

\section{Resultados e discussão}

$\mathrm{Na}$ área estudada observou-se considerável diversidade de plantas invasoras, sendo quantificados 168 indivíduos, dentro destes foram identificadas 18 espécies distribuídas em 8 famílias botânicas, com densidade total de 112 plantas $\mathrm{m}^{-2}$, sendo Astaraceae a família mais representativa, com uma soma de 6 espécies, seguida pelas famílias Poaceae, com 4 espécies, tendo ainda representantes da família Amaranthaceae, Commelinaceae, Cyperaceae, Malvaceae, Pontederiaceae, Rubiaceae e Solanaceae (Tabela 1).

Resultados semelhantes foram encontrados por Soares et al. (2016), observou-se que a maior riqueza de famílias foram: Asteraceae com 15,2\% de espécies, Fabaceae com 12,8\%, seguida por Malvaceae com $12 \%$ e Poaceae e Solanaceae ambas com $8 \%$.

As plantas dicotiledôneas foram predominantes no levantamento com $72,2 \%$ do total das espécies identificadas, resultado próximo ao obtido por Cunha (2014) de 66,6 \%. Mesmo sendo as Asteraceae e Poaceae as famílias mais prevalentes, foram as espécies Nicandra physaloides Gaertn. Solaneceae e Amaranthus hybridus L. Amaranthaceae que se destacaram quanto à frequência, densidade e os demais índices testados. 
Tabela 1. Distribuição das plantas daninhas por família e espécie coletadas.

\begin{tabular}{lcccc}
\hline Espécie & & Família & Nome Comum & Classe \\
\hline Amaranthus hybridus & L. & Amaranthaceae & Caruru Roxo & Dicotiledónea \\
Alternathera tenella & Colla. & Amaranthaceae & Apaga-fogo & Dicotiledónea \\
Blainvillea rhomboidea & Cass. & Asteraceae & Erva-de-palha & Dicotiledónea \\
Acanthospermum hispidum & DC. & Asteraceae & Carrapicho de carneiro & Dicotiledónea \\
Ambrosia tenuifolia & L. & Asteraceae & Altamisa & Dicotiledónea \\
Tridax procumbens & L. & Asteraceae & Erva-de-touro & Dicotiledónea \\
Ageratum cenyzoides & L. & Asteraceae & Mentrasto & Dicotiledónea \\
Conyza canadensis & L. & Asteraceae & Buva & Dicotiledónea \\
Commelina benghalensis & L. & Commelinaceae & Trapoeraba & Dicotiledónea \\
Cyperus esculentus & Linné. & Cyperaceae & Tiririca & Monocotiledónea \\
Sida spinosa & L. & Malvaceae & Vassoura & Dicotiledónea \\
Brachiaria plantaginea & Hitchc. & Poaceae & Papuã & Monocotiledónea \\
Eleusine indica & Gaertn. & Poaceae & Pé-de-galinha & Monocotiledónea \\
Cynodon dactylon & (L.) Pers. & Poaceae & Grama-seda & Monocotiledónea \\
Cenchrus echinatus & L. & Poaceae & Capim-carrapicho & Monocotiledónea \\
Heteranthera sp & Ruiz e Pav & Pontederiaceae & Erva-nova-de-arroz & Dicotiledónea \\
Richardia brasiliesis & Gomes. & Rubiaceae & Poaia & Dicotiledónea \\
Nicandra physaloides & Gaertn. & Solaneceae & Balão & Dicotiledónea \\
\hline
\end{tabular}

A frequência e a densidade com que as espécies ocorreram nas amostras avaliadas pode determinar uma distribuição uniforme ou desuniforme na área, sendo uma alta densidade e baixa frequência um indicativo de distribuição desuniforme. Verificaram-se maiores índices de frequência para Nicandra physaloides Gaertn. Solaneceae, Amaranthus hybridus L. Amaranthaceae e Richardia brasiliesis Gomes. Rubiaceae, tendo estas sido observadas em 100, 83 e 67\% das amostras avaliadas, respectivamente. Já para as maiores densidades foram apresentadas pelas espécies Nicandra physaloides Gaertn. Solaneceae, Amaranthus hybridus L. Amaranthaceae e Eleusine indica Gaertn. Poaceae.

"Á medida que a densidade de plantas daninhas aumenta a competição é intensificada, de modo que as plantas daninhas com maior estatura e mais desenvolvidas tornam-se dominantes" (SANTOS et al., 2004).

A massa seca é influencia pela densidade e pela capacidade competitiva das espécies, portanto, indivíduos que produzem quantidade maior de massa seca em um intervalo menor de tempo possuem maior capacidade competitiva. Assim, nesta amostragem, viu-se que a espécie Nicandra physaloides Gaertn. Solaneceae sobressaiu-se em relação às demais espécies, evidenciado pelo seu porte elevado e grande produção de massa seca.

$\mathrm{O}$ índice de valor de importância que está relacionado à ocorrência, quantidade e concentração de indivíduos nos diferentes pontos amostrados na área total, de uma determinada espécie em relação às demais encontrada na área (SANTOS, 2004) além do acúmulo de massa seca (NASCIMENTO et al., 2011). 
Os IVIr mais elevados, novamente, foram obtidos pelas espécies Nicandra physaloides Gaertn. Solaneceae e Amaranthus hybridus L. Amaranthaceae, além de Richardia brasiliesis Gomes. Rubiaceae e Brachiaria plantaginea Hitchc. Poaceae.

Tabela 2. Médias de frequência (Fre), frequência relativa (Frr \%), densidade (Den plantas $\mathrm{m}^{2}{ }^{2}$ ), densidade relativa (Denr \%), abundância (Abu), abundancia relativa (Abr \%), massa seca de espécies (MS Espéc.) massa seca relativa (MSr \%), índice de valor de importância (IVI \%), e índice de importância relativa (IVIr \%) das plantas daninhas amostradas.

\begin{tabular}{|c|c|c|c|c|c|c|c|c|c|c|}
\hline Espécie & Fre & Frr & Den & Denr & Abu & Abr & $\begin{array}{c}\text { MS } \\
\text { Espéc. }\end{array}$ & $\mathbf{M S r}$ & IVI & IVIr \\
\hline $\begin{array}{l}\text { Nicandra physaloides } \\
\text { Gaertn. Solaneceae }\end{array}$ & 1,0 & 14,6 & 36,00 & 32,1 & 9,00 & 14,1 & 253,48 & 41,04 & 101,9 & 25,47 \\
\hline $\begin{array}{l}\text { Amaranthus hybridus L. } \\
\text { Amaranthaceae }\end{array}$ & 0,8 & 12,2 & 11,33 & 10,1 & 3,40 & 5,31 & 45,39 & 7,35 & 34,98 & 8,74 \\
\hline $\begin{array}{l}\text { Brachiaria plantaginea } \\
\text { Hitchc. Poaceae }\end{array}$ & 0,3 & 4,88 & 8,67 & 7,74 & 6,50 & 10,2 & 33,14 & 5,37 & 28,14 & 7,04 \\
\hline $\begin{array}{l}\text { Richardia brasiliesis } \\
\text { Gomes. Rubiaceae }\end{array}$ & 0,7 & 9,76 & 6,00 & 5,36 & 2,25 & 3,52 & 66,09 & 10,70 & 29,33 & 7,33 \\
\hline $\begin{array}{l}\text { Eleusine indica Gaertn. } \\
\text { Poaceae. }\end{array}$ & 0,5 & 7,32 & 9,33 & 8,33 & 4,67 & 7,29 & 25,25 & 4,09 & 27,03 & 6,76 \\
\hline $\begin{array}{l}\text { Blainvillea rhomboidea } \\
\text { Cass. Asteraceae }\end{array}$ & 0,5 & 7,32 & 8,67 & 7,74 & 4,33 & 6,77 & 24,94 & 4,04 & 25,87 & 6,47 \\
\hline $\begin{array}{l}\text { Cyperus esculentus } \\
\text { Linné. Cyperaceae }\end{array}$ & 0,3 & 4,88 & 4,67 & 4,17 & 3,50 & 5,47 & 46,91 & 7,60 & 22,11 & 5,53 \\
\hline $\begin{array}{l}\text { Heteranthera sp Ruiz e } \\
\text { Pav. Pontederiaceae }\end{array}$ & 0,2 & 2,44 & 5,33 & 4,76 & 8,00 & 12,5 & 24,08 & 3,90 & 23,60 & 5,90 \\
\hline $\begin{array}{l}\text { Cynodon dactylon (L.) } \\
\text { Pers. Poaceae }\end{array}$ & 0,3 & 4,88 & 5,33 & 4,76 & 4,00 & 6,25 & 23,79 & 3,85 & 19,74 & 4,94 \\
\hline $\begin{array}{l}\text { C. benghalensis } \mathrm{L} \text {. } \\
\text { Commelinaceae }\end{array}$ & 0,5 & 7,32 & 4,00 & 3,57 & 2,00 & 3,13 & 17,75 & 2,87 & 16,89 & 4,22 \\
\hline $\begin{array}{l}\text { A. hispidum L. } \\
\text { Amaranthaceae }\end{array}$ & 0,5 & 7,32 & 2,67 & 2,38 & 1,33 & 2,08 & 25,57 & 4,14 & 15,92 & 3,98 \\
\hline $\begin{array}{l}\text { Ambrosia tenuifolia } \mathrm{L} \text {. } \\
\text { Asteraceae }\end{array}$ & 0,2 & 2,44 & 2,67 & 2,38 & 4,00 & 6,25 & 10,45 & 1,69 & 12,76 & 3,19 \\
\hline $\begin{array}{l}\text { Cenchrus echinatus L. } \\
\text { Poaceae }\end{array}$ & 0,2 & 2,44 & 2,00 & 1,79 & 3,00 & 4,69 & 6,90 & 1,12 & 10,03 & 2,51 \\
\hline $\begin{array}{l}\text { Alternathera tenella } \\
\text { Colla. Amaranthaceae }\end{array}$ & 0,2 & 2,44 & 2,00 & 1,79 & 3,00 & 4,69 & 3,19 & 0,52 & 9,43 & 2,36 \\
\hline $\begin{array}{l}\text { Tridax procumbens L. } \\
\text { Asteraceae }\end{array}$ & 0,2 & 2,44 & 1,33 & 1,19 & 2,00 & 3,13 & 2,08 & 0,34 & 7,09 & 1,77 \\
\hline $\begin{array}{l}\text { Ageratum cenyzoides } \mathrm{L} \text {. } \\
\text { Asteraceae }\end{array}$ & 0,2 & 2,44 & 0,67 & 0,60 & 1,00 & 1,56 & 8,07 & 1,31 & 5,90 & 1,48 \\
\hline $\begin{array}{l}\text { Conyza canadensis } \mathrm{L} \text {. } \\
\text { Asteraceae }\end{array}$ & 0,2 & 2,44 & 0,67 & 0,60 & 1,00 & 1,56 & 0,50 & 0,08 & 4,68 & 1,17 \\
\hline
\end{tabular}




\begin{tabular}{lcccccccccc}
\hline $\begin{array}{l}\text { Sida spinosa } \mathrm{L} . \\
\text { Malvaceae }\end{array}$ & 0,2 & 2,44 & 0,67 & 0,60 & 1,00 & 1,56 & 0,04 & 0,01 & 4,60 & 1,15 \\
\hline Totais & $\mathbf{6 , 8}$ & $\mathbf{1 0 0}$ & $\mathbf{1 1 2 , 0 0}$ & $\mathbf{1 0 0}$ & $\mathbf{6 4 , 0}$ & $\mathbf{1 0 0}$ & $\mathbf{6 1 7 , 6 2}$ & $\mathbf{1 0 0}$ & $\mathbf{4 0 0 , 0}$ & $\mathbf{1 0 0}$ \\
\hline
\end{tabular}

\section{Conclusões}

Foram encontradas 8 famílias, 18 espécies num total de 168 indivíduos. As famílias com maior representatividade foram Asteraceae e Poaceae. E a espécie Nicandra physaloides Gaertn. Solaneceae é mais competitiva para área amostrada.

\section{Conflito de Interesse}

Os autores não declararam conflito de interesse para esse manuscrito.

\section{Referências}

ADEGAS, F. S. et al. Levantamento fitossociológico de plantas daninhas na cultura do girassol. Planta Daninha, Viçosa-MG, v. 28, n. 4, p. 705-716, 2010.

CUNHA, J. L. X. L. Fitossociologia de plantas daninhas na cultura do pimentão nos sistemas de plantio direto e convencional. Revista Agro@mbiente On-line, v.8, n.1, p.119-126, 2014.

FALEIRO, F. G.; JUNQUEIRA, N. T. V. Maracujá: o produtor pergunta, a Embrapa responde. - Brasília, DF : Embrapa, 2016. 341 p.

FAO - Food Agriculture Organization of the United Nations. World fertilizer trends and outlook to 2018. Rome, 2015. 66p. http://www.fao.org/3/a-i4324e.pdf. Acesso em 22 mar. 2018.

GAMA, J. C. M. Florística e fitossociologia de plantas espontâneas em comunidades antropizadas do Cerrado em Minas Gerais. 2009, 106f. Dissertação (mestrado), Universidade Federal de Minas Gerais - UFMG, 2009.

IBGE - Instituto Brasileiro de Geografia e Estatística. Anuário Estatístico do Brasil. Rio de Janeiro: IBGE, 1999.

LIMA, A. A.; CARVALHO, J. E. B.; BORGES, A. L. Manejo de plantas infestantes na cultura do maracujá amarelo. Cruz das Almas: Embrapa Mandioca e Fruticultura, 2004. 4 p. (Circular Técnica 70).

MELETTI, L. M. M.; OLIVEIRA, J. C.; RUGGIERO, C. Maracujá. Jaboticabal: FUNEP, 2010. (Série Frutas Nativas, 6).

NASCIMENTO, P. G. M. L.; SILVA, M. G. O da.; FONTES, L. de O.; RODRIGUES, A. P. M. dos S.; MEDEIROS, M. A.; FREITAS, F. C. L. de; Levantamento fitossociológico das comunidades infestantes em diferentes sistemas de plantio de milho. Agropecuária Científica no Semi-Árido, v.7, n. 3, p. 1-9, 2011. 
OLIVEIRA, A.R.; FREITAS, S.P. Levantamento fitossociológico de plantas daninhas em áreas de produção de cana-de-açúcar. Planta daninha vol.26 no.1 Viçosa Jan./Mar. 2008.

OLIVEIRA JÚNIOR, R. S.; CONSTANTIN, J.; INOUE, M. H. Biologia e manejo de plantas daninhas. Curitiba, PR: Omnipax, p. 348, 2011.

SANTOS, M. M. Espaçamento entre fileiras e adubação nitrogenada na cultura do milho. Acta Scientiarum Agronomy, v.29, n.4, p.527-533, 2004.

SOARES FILHO, A. O. et al. Plantas ruderais no Planalto Conquistense, Bahia e sua importância. Natureza on line 14 (2): 027-043. 